\title{
华北地区植物群落的分布格局及构建机制
}

\author{
唐志尧* 刘鸿雁
}

北京大学城市与环境学院, 北京大学生态研究中心, 地表过程分析与模拟教育部重点实验室, 北京 100871

唐志尧, 刘鸿雁 (2019). 华北地区植物群落的分布格局及构建机制. 植物生态学报, 43, 729-731. DOI: 10.17521/cjpe.2019.0248

\section{Distribution patterns and assembly mechanisms of plant communities in North China}

TANG Zhi-Yao* and LIU Hong-Yan

Institute of Ecology, College of Urban and Environmental Sciences, Laboratory for Earth Surface Processes of the Ministry of Education, Peking University, Beijing 100871, China

Tang ZY, Liu HY (2019). Distribution patterns and assembly mechanisms of plant communities in North China. Chinese Journal of Plant Ecology, 43, 729-731. DOI: 10.17521/cjpe.2019.0248

植物群落中蕴藏着丰富的野生植物种质资源, 也为其他生物提供食物和栖息地。在人类文明进步 的历史进程中, 植物群落提供了人类赖以生存的主 要物质资源, 具有不可替代性。由于长期开发和过 度利用, 尤其是最近几十年的高速经济增长, 我国 的自然植物群落资源受到了严重破坏, 如天然林急 剧减少、草地退化、湿地植被萎缩等。植物群落的 退化或消失是我国生态环境质量持续恶化、生物多 样性严重丧失的最根本原因, 开展植物群落资源调 查具有重要的学术意义和应用价值。华北地区植物 群落类型多样, 但长期以来受到人类活动的强烈影 响, 在中国具有代表性。2011年7月, 国家科技部科 技基础性工作专项启动了 “华北地区自然植物群落 资源综合考察”项目(2011FY110300)。该项目组织了 10 个科研院校单位, 对华北地区的自然植物群落开 展全面的清查, 对重要的类型和重点区域开展了详 细调查。本专辑是对该成果的概括和总结。

项目在启动之初, 基于项目组成员长期群落调 查的经验, 充分吸收国内外植物群落的研究成果 (方精云等, 2009), 制定了一套我国植物群落调查的 技术规范和方法体系, 用于本项目的实施, 并为今 后其他区域的群落调查提供标准和规范。严格、统 一的调查标准和技术规范确保了样地布局的系统性 和数据收集的科学性和统一性。该规范对群落样方 的布点、设置、样方大小及形状、调查项目、生态
属性和生境因子的测定项目进行了统一规范和标准 制定; 考虑到不同植被类型的调查方法和观测项目 的差异, 分别为森林、灌丛、草地和湿地(含水体) 等不同类型编制了规范和标准。

1. 样地布局与样方设置。项目从基准点调查、 清查以及精查 3 个层次设置样地。基准点调查的目的 是全面掌握华北地区的植物群落现状, 按 $0.5^{\circ} \times$ $0.5^{\circ}$ 经纬网格进行机械布点, 对各点进行群落调查, 部分样点进行环境因子和生态属性测定; 清查的目 的是了解不同区域的群落分布现状，在自然植物群 落分布的重点区域, 综合考虑自然植物群落的分布 类型和复杂程度、系统性、代表性、可达性, 设置 群落清查样点, 主要进行群落调查; 精查的目的是 掌握地带性植物群落的组成、结构与分布, 在以上 重点区域清查样方的基础上, 重点调查地带性植物 群落, 精查内容包括植物群落调查、土壤调查以及 植物属性调查。

2. 森林植物群落清查。森林是本项目重点调查 的植被类型。调查样方的面积设为 $30 \mathrm{~m} \times 20 \mathrm{~m}$, 观 测记录包括乔木层、灌木层、草本层和层间植物(方 精云等, 2009)。具体调查内容如下: (1)乔木层: 记录 样方内出现的全部乔木种, 测量所有胸径 $(D B H) \geqslant 3$ $\mathrm{cm}$ 的植株 $D B H$ 和高度, 记录其存活状态。(2)灌木层: 记录样方内出现的全部灌木种。选择两个面积 $10 \mathrm{~m}$ $\times 10 \mathrm{~m}$ 的对角小样方进行灌木调查, 对其中全部灌 
木分种计数。(3)草本层: 记录样方内出现的全部草 本种类。测量和记录样方的四角和中心点上共 5 个 1 $\mathrm{m} \times 1 \mathrm{~m}$ 的草本层样方中, 每种草本植物的多度、盖 度和高度。(4)层间植物: 记录出现的全部寄生、附 生植物和攀援藤本植物种类, 并估计其多度和盖度 (方精云等, 2009)。(5)样方环境因子: 包括经纬度、 海拔、坡向、坡度、坡位、干扰状况。(6)土壤理化 性状测定：在精查和基准点样方内, 取完整土壤剖 面一个, 测定不同深度的土壤质地、容重、有机碳 含量、全氮含量、全磷含量、 $\mathrm{pH}$ 等理化性质。

3. 灌从、草地及水生植物群落清查: 全面清查 华北地区灌从、草地和水生植物群落类型、物种组 成、生境特征、季相变化等。灌丛和草地样方面积 为 $10 \mathrm{~m} \times 10 \mathrm{~m}$, 具体调查内容包括物种构成、物种 多度、盖度和高度、样方环境因子。土壤理化性状 分析参照森林样地。水生植物群落主要调查物种构 成、物种多度和盖度及环境因子。

4. 重要植物生态属性的测定: 为了反映植物群 落的主要功能特征, 选择优势物种进行其生态属性 的采样和观测。具体观测指标包括: (1)叶属性: 叶片 比叶面积、碳氮磷含量、叶大小、叶厚度、叶解剖 特征等; (2)根系属性: 比根长、碳氮磷含量等; (3)枝 干属性: 树皮厚度、木材密度、心材/边材比率等。

经过6年的调查研究, 项目组完成了华北地区 森林、灌从、草地及水生植物群落的详细调查, 研 究了该区域植物群落分布格局及其构建机制, 并评 估了该区域的群落利用和保护现状。本专辑共收录 11篇论文，集中报道项目的相关研究成果。

华北地区森林植被长期遭受人类活动的破坏, 残存的森林植被呈片段化分布。本专辑论文的主题 涉及森林群落构建、演替、物种多样性以及对全球 变化的敏感性等多个热点, 不仅系统地分析了栎 (Quercus) 林等优势的森林类型, 还探讨了落叶松 (Larix)林、胡桃楸(Juglans mandshurica)林等温带地 区有特色的森林类型。研究结果表明环境热量主导 了华北地区森林群落的谱系关系, 生境过滤在森林 群落构建中的作用随着年降水量的增加逐渐加强 (许金石等, 2019)。发现中国北方3种落叶松林的林 分径级及树高均为右偏分布, 3 种落叶松林均处于相 对稳定的演替阶段, 其最大胸径和最大树高及物种 丰富度均受年降水量影响(方文静等, 2019)。海拔、 坡度、坡位和人为干扰程度是影响华北地区胡桃楸
林空间分布的主要因子, 生态位分化主导了群落内 的物种共存, 其中河北、陕西、天津的胡桃楸林物 种共存过程主要受负密度制约的影响, 北京、山西 的胡桃楸林的物种共存过程主要受环境选择驱动 (唐丽丽等, 2019b)。环境差异对关帝山森林木本植 物的 $\beta$ 多样性具有相对较强的作用; 而环境差异和 地理距离共同作用于草本植物的 $\beta$ 多样性(秦浩等, 2019)。面对全球变化, 张雪晈等(2019)利用物种分 布模型研究了未来气候变化对华北及周边地区 5 种 栎属植物多度的影响, 他们发现未来气候变化背景 下，在超过一半面积的分布区，麻栋(Q. acutissima)、槲栎 $(Q$. aliena)、锐齿葪栋( $Q$. aliena var. acuteserrata) 和辽东栋 (Q. wutaishanica) 的多度减 少。邹安龙等(2019)发现北京东灵山辽东栋林中不 同树种对氮的敏感度不一样, 氮添加促进了辽东栋 但抑制了大叶白蜡(Fraxinus rhynchophylla)的生长。

华北地区灌从类型多样，分布广泛，本专辑论 文较为系统地探讨了灌从群落的分类以及群落特 征。华北地区的灌丛可以划分为 5 种植被型 195 个群 系, 灌从草本层的系统发育结构表现为发散模式, 而灌木层的系统发育结构表现为聚集模式(柴永福 等, 2019)。唐丽丽等(2019a)发现华北地区荆条(Vitex negundo var. heterophylla)灌从灌木层和草本层的物 种多样性分布格局差异较大, 灌木层物种丰富度随 着纬度的降低而降低，随着海拔的升高而降低，而 草本层物种多样性则相反。李紫晶等(2019)总结了 内蒙古西鄂尔多斯地区特有的荒漠半日花(Helianthemum songaricum)群落的分布、群落特征及其分类, 发现半日花群落区系地理成分以中亚东部成分为主, 并根据生活型和优势度, 将半日花群落划分为半日 花-草本荒漠、半日花-灌木-草本荒漠、半日花-半灌 木荒漠 3 个群丛组共 10 个群丛。吴盼等(2019)等发现 山东省滨海湿地柽柳(Tamarix chinensis)种群在小尺 度(小于 $5 \mathrm{~m}$ )上表现为聚集分布，在大尺度(大于 15 $\mathrm{m})$ 上表现为随机分布，总体表现为随空间尺度的增 大, 柽柳种群呈现由聚集分布过渡到随机分布的趋 势; 不同径级两两之间在小尺度上表现为正关联, 在大尺度上表现为无关联性。

本专辑也包括了对草本群落的研究, 施晶晶等 (2019)发现扩散限制与环境过滤共同主导了黄土高 原腹地人工林下草本层群落的构建过程。

虽然本专辑没有涵盖华北地区所有的植被类型， 
但对该区域典型植物群落的物种组成、群落构建机 制以及生物多样性分布格局等的研究, 均有助于了 解华北这一人类活动剧烈地区的植被分布、演替、 生物多样性等主要特征及植被利用与保护策略。

致谢 感谢“华北自然植物群落资源综合清查”项目 顾问方精云院士对项目的申请、设计和运行给予的 指导, 感谢本项目所有参加人员的辛苦付出。项目 研究骨干包括: 高贤明、郭卫华、韩文轩、贺金生、 黄永梅、吉成均、江源、康慕谊、李方民、梁存柱、 刘春花、刘全儒、刘晓、马文红、石福臣、王立新、 王玛丽、王仁卿、肖克炎、徐新伟、于丹、岳明、 张峰、张殷波、郑成洋。

\section{参考文献}

Chai YF, Xu JS, Liu HY, Liu QR, Zheng CY, Kang MY, Liang CZ, Wang RQ, Gao XM, Zhang F, Shi FC, Liu X, Yue M (2019). Species composition and phylogenetic structure of major shrublands in North China. Chinese Journal of Plant Ecology, 43, 793-805. [柴永福, 许金石, 刘鸿雁, 刘全儒, 郑成洋, 康慕谊, 梁存柱, 王仁卿, 高贤明, 张峰, 石福 臣, 刘晓, 岳明 (2019). 华北地区主要灌从群落物种组 成及系统发育结构特征. 植物生态学报, 43, 793-805.]

Fang JY, Wang XP, Shen ZH, Tang ZY, He JS, Yu D, Jiang Y, Wang ZH, Zheng CY, Zhu JL, Guo ZD (2009). Methods and protocols for plant community inventory. Biodiversity Science, 17, 533-548. [方精云, 王襄平, 沈泽昊, 唐志 尧, 贺金生, 于丹, 江源, 王志恒, 郑成洋, 朱江玲, 郭 兆迪 (2009). 植物群落清查的主要内容、方法和技术规 范. 生物多样性, 17, 533-548.]

Fang WJ, Cai Q, Zhu JL, Ji CJ, Yue M, Guo WH, Zhang F, Gao XM, Tang ZY, Fang JY (2019). Distribution, community structures and species diversity of larch forests in North China. Chinese Journal of Plant Ecology, 43, 742-752. [方文静, 蔡琼, 朱江玲, 吉成均, 岳明, 郭卫华, 张峰, 高 贤明, 唐志尧, 方精云 (2019). 华北地区落叶松林的分布、 群落结构和物种多样性. 植物生态学报, 43, 742-752.]

Li ZJ, Sha N, Shi YB, Tong XZ, Dong L, Zhang XQ, Sun Q, Liang CZ (2019). Classification and characteristics of $\mathrm{He}$ lianthemum songaricum communities in western Erdos region, Nei Mongol, China. Chinese Journal of Plant Ecology, 43, 806-816. [李紫晶, 莎娜, 史亚博, 佟旭泽, 董雷, 张小 青, 孙蓄, 梁存柱 (2019). 内蒙古西鄂尔多斯地区半日花 荒漠群落特征及其分类. 植物生态学报, 43, 806-816.]

Qin H, Zhang YB, Dong G, Zhang F (2019). Altitudinal patterns of taxonomic, phylogenetic and functional diversity of forest communities in Mount Guandi, Shanxi, China. Chinese Journal of Plant Ecology, 43, 762-773. [秦浩, 张 殷波, 董刚, 张峰 (2019). 山西关帝山森林群落物种、谱 系和功能多样性海拔格局. 植物生态学报, 43, 762-773.]
Shi JJ, Zhao MF, Wang YH, Xue F, Kang MY, Jiang Y (2019). Community assembly of herbaceous layer of the planted forests in the central Loess Plateau, China. Chinese Journal of Plant Ecology, 43, 834-842. [施晶晶, 赵鸣飞, 王宇 航, 薛峰, 康慕谊, 江源 (2019). 黄土高原腹地人工林下 草本层群落构建机制研究. 植物生态学报, 43, 834-842.]

Tang LL, Yang T, Liu HY, Kang MY, Wang RQ, Zhang F, Gao XM, Yue M, Zhang M, Zheng PF, Shi FC (2019a). Distribution and species diversity patterns of Vitex negundo var. heterophylla shrublands in North China. Chinese Journal of Plant Ecology, 43, 825-833. [唐丽丽, 杨 䑣, 刘鸿雁, 康慕谊, 王仁卿, 张峰, 高贤明, 岳明, 张 梅, 郑璞帆, 石福臣 (2019a). 华北地区荆条灌从分布及 物种多样性空间分异规律. 植物生态学报, 43, 825-833.]

Tang LL, Zhang M, Zhao XL, Kang MY, Liu HY, Gao XM, Yang T, Zheng PF, Shi FC (2019b). Species distribution and community assembly rules of Juglans mandshurica in North China. Chinese Journal of Plant Ecology, 43, 753-761. [唐丽丽, 张梅, 赵香林, 康慕谊, 刘鸿雁, 高贤明, 杨 䑣，郑璞帆，石福臣 (2019b). 华北地区胡桃楸林分布 规律及群落构建机制分析. 植物生态学报, 43, 753-761.]

Wu P, Peng XQ, Yang SR, Gao YN, Bai FH, Yi SJ, Du N, Guo WH (2019). The spatial distribution patterns and correlation of Tamarix chinensis population in coastal wetlands of Shandong Province, China. Chinese Journal of Plant Ecology, 43, 817-824. [吴盼, 彭希强, 杨树仁, 高亚男, 白丰桦, 衣世杰, 杜宁, 郭卫华 (2019). 山东省滨海湿 地柽柳种群的空间分布格局及其关联性. 植物生态学 报, 43, 817-824.]

Xu JS, Chai YF, Liu X, Yue M, Guo YX, Kang MY, Liu QR, Zheng CY, Ji CJ, Yan M, Zhang F, Gao XM, Wang RQ, Shi FC, Zhang QD, Wang M (2019). Community assembly, diversity patterns and distributions of broad-leaved forests in North China. Chinese Journal of Plant Ecology, 43, 732-741. [许金石, 柴永福, 刘晓, 岳明, 郭圭金金, 康慕 谊, 刘全儒, 郑成洋, 吉成均, 间明, 张峰, 高贤明, 王仁 卿, 石福臣, 张钦弟, 王茂 (2019). 华北区域环境梯度上 阔叶林构建模式及分布成因. 植物生态学报, 43, 732-741.]

Zhang XJ, Gao XM, Ji CJ, Kang MY, Wang RQ, Yue M, Zhang F, Tang ZY (2019). Response of abundance distribution of five Quercus species to climate change in northern China. Chinese Journal of Plant Ecology, 43, 774-782. [张雪皎, 高贤明, 吉成均, 康慕谊, 王仁卿, 岳明, 张 峰, 唐志尧 (2019). 中国北方5种栎属树木多度分布及 其对未来气候变化的响应. 植物生态学报, 43, 774-782.]

Zou AL, Li XP, Ni XF, Ji CJ (2019). Responses of tree growth to nitrogen addition in Quercus wutaishanica forests in Mt. Dongling, Beijing, China. Chinese Journal of Plant Ecology, 43, 783-792. [邹安龙, 李修平, 倪晓凤, 吉成均 (2019). 模拟氮沉降对北京东灵山辽东栎林树木生长的 影响. 植物生态学报, 43, 783-792.]

责任编委: 郭 柯 责任编辑: 谢 巍 